\title{
Immune parameters identify Italian centenarians with a longer five-year survival independent of their health and functional status
}

\author{
L. Bucci ${ }^{\mathrm{a}, 1}$, R. Ostan ${ }^{\mathrm{a}, 1}$, E. Giampieri ${ }^{\mathrm{c}}$, E. Cevenini ${ }^{\text {a }}$, E. Pini ${ }^{\mathrm{a}}$, M. Scurti ${ }^{\text {a }}$, R. Vescovini ${ }^{\mathrm{d}}$, P. Sansoni ${ }^{\mathrm{d}}$, C. Caruso $^{\mathrm{e}}$, \\ D. Mari f,g, F. Ronchetti f,g, M.O. Borghi f,g, G. Ogliari ${ }^{\text {f,g }}$, C. Grossi ${ }^{\text {g,h }}$, M. Capri ${ }^{\text {a,b }}$, S. Salvioli ${ }^{\text {a,b }}$, G. Castellani ${ }^{\text {b,c }}$, \\ C. Franceschi ${ }^{\text {a,b,* }}$, D. Monti ${ }^{i}$
}

${ }^{\text {a }}$ Department of Experimental, Diagnostic and Specialty Medicine, University of Bologna, Bologna, Italy

b CIG-Interdepartmental Centre L. Galvani, University of Bologna, Bologna, Italy

c Physics and Astronomy Department, University of Bologna, Bologna, Italy

d Department of Clinical and Experimental Medicine, University of Parma, Parma, Italy

e Immunosenescence Unit, Department of Pathobiology and Biomedical Methodologies, University of Palermo, Palermo, Italy

${ }^{\mathrm{f}}$ Geriatric Unit IRCCS Ca' Granda Foundation Maggiore Policlinico Hospital, University of Milan, Italy

${ }^{g}$ Department of Clinical Sciences and Community Health, University of Milan, Italy

${ }^{\mathrm{h}}$ Experimental Laboratory of Immuno-rheumatology, IRCCS Istituto Auxologico Italiano, Milan, Italy

${ }^{i}$ Department of Clinical and Experimental Biomedical Sciences, University of Florence, Florence, Italy

\section{A R T I C L E I N F O}

\section{Article history:}

Received 6 November 2013

Received in revised form 22 January 2014

Accepted 24 January 2014

Available online 31 January 2014

Section Editor: Daniela Frasca

\section{Keywords:}

Centenarians

Survival

Immune system

Health status

Cluster analysis

\begin{abstract}
A B S T R A C T
Centenarians are rare and exceptional individuals characterized by a peculiar phenotype. They are the best example of healthy aging in humans as most of them have escaped or substantially delayed the onset of major age-related diseases. Within this scenario, the purpose of the present work was to understand if immune status is associated with survival and health status in centenarians. To this aim, 116 centenarians were concomitantly characterized for their immunological, health and functional status, and followed-up for five-year survival. On the basis of previous knowledge we focused on a core of fundamental and basic immune parameters (number of leukocytes, monocytes, total lymphocytes, $\mathrm{CD}^{+}{ }^{+} \mathrm{T}$ lymphocytes, $\mathrm{CD} 4^{+}$helper $\mathrm{T}$ lymphocytes, $\mathrm{CD} 8^{+}$cytotoxic T lymphocytes, CD19+ B lymphocytes and plasma levels of IgM), and the most important findings can be summarized as follows: i. a hierarchical cluster analysis was able to define Cluster1 (88 centenarians) and Cluster2 ( 28 centenarians) characterized by low and high values of all these immune parameters, respectively; ii. centenarians of Cluster2 showed a statistically longer five-year survival and more favorable values of other important immune (naïve, activated/memory and effector/memory T cells) and metabolic (glycemia, insulin and HOMA-IR) parameters, in accord with previous observations that centenarians have a peculiar immune profile, a preserved insulin pathway and a lower incidence of type 2 diabetes; and iii. unexpectedly, parameters related to frailty, as well as functional and cognitive status, did not show any significant correlation with the immune clustering, despite being capable per se of predicting survival. In conclusion, high values of basic immunological parameters and important $\mathrm{T}$ cell subsets correlate with five-year survival in centenarians, independent of other phenotypic characteristics. This unexpected biological scenario is compatible with the general hypothesis that in centenarians a progressive disconnection and loss of biological coherence among the different functions of the body occur, where survival/mortality result from the failure of any of these domains which apparently follow an independent age-related trajectory.
\end{abstract}

(c) 2014 Elsevier Inc. All rights reserved.

\section{Introduction}

During the last century human life expectancy is more than doubled and nowadays the number of the oldest old is increasing worldwide. Accordingly, the number of centenarians is expected to increase and about

\footnotetext{
* Corresponding author at: Department of Experimental, Diagnostic and Specialty Medicine, University of Bologna, Bologna, Italy. Tel.: + 3905120947 43; fax: + 39051 2094747.

E-mail address: claudio.franceschi@unibo.it (C. Franceschi).

1 These authors contributed equally to the manuscript.
}

157,000 centenarians in Italy (total population $61 \mathrm{M}$ ) are foreseen on 2050 (World Population Prospects. The 2012 Revision). The increased number of centenarians in recent decades is mainly due to a dramatic decline in the mortality rate among 80 -year old individuals (Jeune, 2002). Certainly, centenarians show a complex and heterogeneous phenotype determined by an improved ability to adapt and remodel in response to physical and chemical agents, psychological stress and biological stimuli such as viral, bacterial and tumor antigens (Franceschi et al., 2008). These extraordinary individuals reached the extreme limits of human life by slowing down the aging process and, in most cases, delaying, avoiding or surviving to the major age- 
associated diseases. In fact, centenarians show a lower prevalence of cancer (Salvioli et al., 2009), cardiovascular diseases (Olivieri et al., 2008), insulin resistance and diabetes (Paolisso et al., 2001) and they manage to delay the onset of dementia, Alzheimer's disease and osteoporotic fractures of about one or two decades on average (Evert et al., 2003; Passeri et al., 2003). On the other hand, extreme aging is accompanied by an increased morbidity due to a decreased ability of the immune system to cope with new antigenic challenges and to control chronic infections. Indeed, mortality due to infectious diseases continues to accelerate also in very late life, different from all the other mortality causes (Pawelec et al., 2006). The age-associated immune deregulation is due to changes in innate and adaptive immunity (Franceschi et al., 1995; Alberti et al., 2006; Nasi et al., 2006; Ostan et al., 2008; Sansoni et al., 2008) and is associated with chronically elevated markers of systemic inflammation (Cevenini et al., 2013a). Several studies have examined the relationship between survival and immune parameters in longitudinal studies of very old population. The Swedish longitudinal OCTO and NONA immune studies identified immune features mostly involving the main lymphocyte subsets such as, high CD8 percentages, low CD4 and CD19 percentages, a persistent inverted $\mathrm{CD} 4 / \mathrm{CD} 8$ ratio, poor T-cell proliferative responses and seropositivity to Cytomegalovirus (CMV), defining an Immune Risk Phenotype (IRP), and associated with mortality (Ferguson et al., 1995; Wikby et al., 1998, 2002). Subsequently, the same authors showed that mortality-associated IRP was largely independent of morbidity in a sample of very old subjects (Nilsson et al., 2003). The analysis at 6year follow-up of the same cohort showed that individuals surviving until the age of 100 years did not display T-cell changes associated with IRP, maintaining low numbers of $\mathrm{CD}^{+} \mathrm{CD}^{-} 8^{-}, \mathrm{CD}^{+}{ }^{+} \mathrm{CD} 8^{+}$and $\mathrm{CD}^{+} \mathrm{T}$ cells and high $\mathrm{CD} 4 / \mathrm{CD} 8$ ratio (Strindhall et al., 2007). Conversely, Huppert et al. found that low percentage of $\mathrm{CD}^{+}$and $\mathrm{CD} 19^{+}$ lymphocytes were associated with poor survival in elderly (Huppert et al., 2003). In a cohort of $85+$ year old subjects followed for 10 years low peripheral blood lymphocyte count as well as low number of $\mathrm{CD}^{+}, \mathrm{CD}^{+}$and $\mathrm{CD} 16^{+}$lymphocytes was associated with an increased risk of mortality in subjects without apparent disease (Izaks et al., 2003). Furthermore, the humoral immune response is quantitatively and qualitatively impaired during aging and the reduced response against new infectious agents and vaccines is often due to a decreased $B$ cell count, reduced antibody specificity, affinity, and isotype switch in elderly people (Frasca and Blomberg, 2011). Thus, B cell number should be considered among the hallmarks of successful or unsuccessful aging (Colonna-Romano et al., 2010).

Owing to the few papers addressing the immune status of centenarians and the lack of data on the relationship between their immune status and survival, we here present data showing that a core of basic immune parameters correlates with survival independent of health and functional status. These data are compatible with the general hypothesis that the body of very old subjects undergoes a profound change where different domains (immune, functional and cognitive) loose the tight functional interconnection inherent in younger bodies.

\section{Materials and methods}

\subsection{Subjects}

A total of 116 centenarians (mean age years: 100.7, age range: 99-111 years, 23 males and 93 females) were enrolled from four Italian cities (Bologna, Milan, Florence and Parma) and the surrounding areas. The list of centenarians was obtained by the local Register Offices. The study protocol was approved by the Ethical Committee of Sant'Orsola-Malpighi University Hospital (Bologna, Italy). After obtaining a written informed consent, a standard questionnaire was administered by trained physicians and nursing staff to collect demographic and lifestyle data, anthropometric measurements, functional, cognitive and health status, clinical anamnesis, and details on drug use. In all cases where the subject was unable to participate in full due to compromised health and/or cognitive ability the interview was performed with a relative or a caregiver.

\subsection{Data collection}

Body weight was measured using standard weighing scales (SECA Mod. 761) calibrated in kilograms. Height was measured at head level to the nearest centimeter with the subject standing barefoot, feet together, using a standard tape measure calibrated in centimeters. Body mass index (BMI) was calculated as weight in kilograms divided by the square of the height in meters $\left(\mathrm{kg} / \mathrm{m}^{2}\right)$. Waist circumference was measured to the nearest centimeter by wrapping a flexible steel tape at the level of the umbilicus at the end of exhalation, with the subject standing. Past and current disease histories were accurately recorded by addressing the major age-related pathologies: myocardial infarction, stroke, cerebral thrombosis and hemorrhage, cancer, cardiovascular diseases, hypertension, chronic obstructive pulmonary disease, hypercholesterolemia, diabetes, hyperthyroidism, hypothyroidism, osteoporosis and chronic renal insufficiency. Current use of medication (including inspection of the drugs by the interviewer) was recorded, and the drugs were grouped into four main categories: cardiovascular (antiarrhythmic and/or vasodilator and/or thrombolytic drugs), hypotensive (calcium channel blockers and/or ACE inhibitors and/or diuretics and/or beta blockers), lipid-lowering (statins and/or fibrates and/or other hypolipidemic agents), and anti-diabetic (sulfonylureas and/or biguanides and/or insulin and insulin analogs and/or other oral antidiabetic association) therapies.

Functional status was assessed by Activities of Daily Living scale (ADL, scores ranging from 0 [all functions lost] to 5 [all functions preserved]) and subjects were grouped as "Not disabled" those who were independent in all the 5 domains or as "Moderately/Severely disabled" the others (Katz et al., 1970; Nybo et al., 2003). Continence was analyzed separately in accordance with the recommendations in the literature (Fillenbaum, 1996). Ability in home management was assessed by Instrumental Activities of Daily Living scale (IADL, scores ranging from 0 [all functions lost] to 8 [all functions preserved]) (Lawton and Brody, 1969).

Physical performance was assessed by self-reported data regarding the ability to walk $500 \mathrm{~m}$, to go up and down the stairs and the use of aids. Moreover, Handgrip Strength test and Chair Stand test were performed, the former to measure the maximum isometric strength of the hand and forearm muscles and the latter to evaluate leg strength and endurance measuring the time it takes to perform 5 repetitions of sit-to-stand (Csuka and McCarty, 1985). Handgrip strength was measured using a hand-held dynamometer (SMEDLYS' dynamometer, Scandidact, Kvistgaard, Denmark) for two performances with each hand. Regarding the Chair Stand test, centenarians were considered able or unable to complete the test. The cognitive status was assessed by Standardized Mini-Mental State Examination test (SMMSE) (Folstein et al., 1975) and the mood was investigated by the Geriatric Depression Scale (GDS, short form, 15 items) (Yesavage et al., 1982). Frailty was defined according to the Study of Osteoporotic Fractures (SOF) index as the presence of $\geq 2$ of the following 3 components: 1 . weight loss (irrespective of intention to lose weight) of more than $5 \%$ in the previous year; 2 . inability to rise from a chair five times without using the arms; and 3. poor energy as identified by an answer of "no" to the question "Do you feel full of energy?" on the GDS. Centenarians were classified as "Frail" if they met $\geq 2$ of the 3 criteria, as "Pre-frail" if they met 1 or as "Robust" if they met none (Ensrud et al., 2008).

Simple Model of Functional Status (SMFS) was adopted to classify centenarians in two groups according to their health status. Cognitively intact and not disabled centenarians (SMMSE $\geq 24$ and ADL $=5$ ) were defined as "Healthy/independent" while centenarians displaying either cognitive impairment or functional disability (SMMSE $<24$ or ADL $<5$ ) were defined as "Unhealthy/dependent" (Cevenini et al., 2013b). 
All participants were followed for mortality during a period of 5 years. The copies of death certificates indicating the places and dates of death were obtained from the Register Offices.

\subsection{Laboratory measurements}

Overnight fasting blood samples were obtained early in the morning. Serum was removed after clotting and centrifugation at $760 \times \mathrm{g}$ for 20 min, rapidly frozen and stored at $-80^{\circ} \mathrm{C}$. Serum creatinine, total and HDL cholesterol, triglycerides, and glycemia were measured using standard hematology methods. Serum insulin was measured using a chemiluminescent immunoassay (LIAISON ${ }^{\circledR}$ Insulin Assay, DiaSorin, Saluggia, Italy), and samples were analyzed on the LIAISON ${ }^{\circledR}$ Analyzer (DiaSorin). Insulin resistance status was assessed using the Homeostasis Model Assessment of Insulin Resistance (HOMA-IR), according to the previously described formula (Matthews et al., 1985): insulin (in microunits per milliliter) $\times$ glucose (in millimoles per liter)/22.5. Subjects with an HOMA-IR $\geq 2.5$ were considered insulin resistant.

\subsection{Flow cytometric analysis of T cell phenotype}

The analysis of the principal lymphocyte subsets was standardized among the centers. The phenotypical analysis was performed on whole blood within $3 \mathrm{~h}$ from blood withdrawal. All the recruiting centers used the same monoclonal antibodies (mAbs) purchased from BD Biosciences (BD Biosciences, San Jose, CA) and followed adequate training and instructions for acquisition at flow cytometer. Surface staining was performed on heparinized whole blood using the following mAbs: anti-CD5-FITC/anti-CD19-PE; anti-CD4-FITC/anti-CD8-PE/antiCD3-PE-Cy7; anti-CD28-FITC/anti-CD95-PE/anti-CD4-PE-Cy7 or antiCD8-PE-Cy7. Isotype-matched irrelevant antibodies were used to set fluorescence markers and to identify non-specific binding. Briefly 100 $\mu \mathrm{l}$ of whole blood were incubated with saturating amount of the mAbs for $30 \mathrm{~min}$ at $4{ }^{\circ} \mathrm{C}$ in the dark and then were lysed with FACS Lysing Solution (BD Biosciences). Acquisition and analysis were performed on a FACSCalibur instrument (BD Biosciences) using Cell Quest software (BD Biosciences). Files were gated on lymphocytes identified by the FSC and SSC parameters and then $\mathrm{CD}^{+}$T lymphocytes were gated into $\mathrm{CD}^{+}{ }^{+}$helper and $\mathrm{CD} 8^{+}$cytotoxic T lymphocytes. After a gate on lymphocytes, $\mathrm{CD} 4^{+}$helper and $\mathrm{CD} 8$ bright ${ }^{+}$cytotoxic $\mathrm{T}$ cells were gated into naïve $\left(\mathrm{CD} 28^{+} \mathrm{CD} 95^{-}\right)$, activated/memory $\left(\mathrm{CD} 28^{+} \mathrm{CD} 95^{+}\right)$, and effector/memory $\left(\mathrm{CD} 28^{-} \mathrm{CD} 95^{+}\right)$subsets as previously published (Fagnoni et al., 2000). To obtain the absolute numbers we used total lymphocyte count from quality certified clinical laboratory analysis. The absolute number of total, naïve, activated/memory and effector/ memory $\mathrm{CD}^{+}{ }^{+}$helper and $\mathrm{CD} 8^{+}$cytotoxic $\mathrm{T}$ cells per $\mu \mathrm{l}$ of peripheral blood was calculated multiplying lymphocyte count by the frequency of different subsets in the lymphocyte gate.

\subsection{Statistical analysis}

On the basis of previous knowledge (Ferguson et al., 1995; Wikby et al., 1998, 2002) we focused on the following eight basic immune parameters: number of leucocytes, monocytes, total lymphocytes, $\mathrm{CD}^{+} \mathrm{T}$ lymphocytes, $\mathrm{CD} 4^{+}$helper and $\mathrm{CD} 8^{+}$cytotoxic Tlymphocytes, $\mathrm{CD} 19^{+} \mathrm{B}$ lymphocytes and levels of plasma IgM. These immune parameters were $\log$ transformed and standardized to improve their normality and used in a Cluster Analysis (CA) to identify different groups of centenarians. This analysis was performed with a Hierarchical Clustering using a Ward linkage method (Ward, 1963). The results of the clustering were robust to a variation on different linkage methods. Moreover, the eight immune parameters were transformed with a PCA in which the first component explains the $45 \%$ of the variation in the data. Comparing the clustering with the PCA we found that the cluster separation is along the principal axes of the PCA. The clusters were balanced by gender, as tested with an exact Fisher test ( $p$ value $=0.8$ ), so a correction for gender was not required, and the age is already almost constant between the subjects.

Differences between two clusters were assessed by Chi square or Fisher exact tests for categorical variables and Independent Sample $t$ test or Mann-Whitney U test for continuous variables as appropriate.

Kaplan-Meier survival curves were used to display five-year allcause mortality according to Cluster Analysis, to Frailty Status (SOF index) and to the Simple Model of Functional Status (SMFS).

Univariate Cox regression model was used to address the association between each of the eight immune parameters used in the Cluster Analysis with the five-year survival. Multivariate Cox regression models were used to test the interaction between Cluster Analysis, SOF index and SMFS and to evaluate their association with survival. A significance level of a $\mathrm{p}<0.05$ was chosen in all the tests. All analyses were executed using R software, Python statistical libraries (statsmodels, pandas and scipy packages) and SPSS 19.0 for windows (SPSS Inc., Chicago, IL, USA).

\section{Results}

According to the abovementioned studies (Ferguson et al., 1995; Wikby et al., 1998, 2002) suggesting that few basic immune parameters are capable of grasping the main characteristics of the immune status in the oldest old, we focused on a core of eight basic immune parameters which in a Cluster Analysis (CA) were able to separate two groups of centenarians. We further showed that these two groups have a significantly different five-year survival, independent of their health and functional status.

In particular, a hierarchical CA was used to identify groups of centenarians homogeneous for the combination of 8 immune parameters, i.e. number of leucocytes, monocytes, total lymphocytes, $\mathrm{CD}^{+} \mathrm{T}$ lymphocytes, $\mathrm{CD} 4^{+}$helper and $\mathrm{CD}^{+}$cytotoxic $\mathrm{T}$ lymphocytes, $\mathrm{CD} 19^{+}$

Table 1

Baseline characteristics and immune variables of centenarians according to CA.

\begin{tabular}{|c|c|c|c|}
\hline & Cluster1 & Cluster2 & $\mathrm{p}$ value \\
\hline Number, n (\%) & $88(75.9)$ & $28(24.1)$ & \\
\hline Male/female, n & $17 / 71$ & $6 / 22$ & 0.807 \\
\hline Age, years, mean \pm S.D. & $100.7 \pm 2.0$ & $100.9 \pm 1.9$ & 0.529 \\
\hline \multicolumn{4}{|l|}{ Immune parameters } \\
\hline Leucocytes, cells $10^{3} / \mu \mathrm{l}$ & $5.9 \pm 1.4$ & $7.5 \pm 1.9$ & $<0.001$ \\
\hline Lymphocytes, cells $10^{3} / \mu \mathrm{l}$ & $1.4 \pm 0.4$ & $2.2 \pm 0.7$ & $<0.001$ \\
\hline Monocytes, cells $10^{3} / \mu \mathrm{l}$ & $0.3 \pm 0.1$ & $0.5 \pm 0.2$ & $<0.001$ \\
\hline 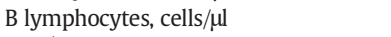 & $54.9(0.23-278.0)$ & $89.9(19.3-1388.7)$ & $<0.001$ \\
\hline $\mathrm{CD}^{+}{ }^{+} \mathrm{T}$ lymphocytes, cells/ $\mu \mathrm{l}$ & $796.8(294.8-1570.3)$ & $1566.5(950.0-2690.7)$ & $<0.001$ \\
\hline $\mathrm{CD}^{+}{ }^{+}$Helper T lymphocytes, cells/ $\mu \mathrm{l}$ & $460.9(187.4-972.6)$ & $902.6(623.8-1604.8)$ & $<0.001$ \\
\hline $\mathrm{CD}^{+}$cytotoxic t lymphocytes, cells/ $\mu \mathrm{l}$ & $245.2(64.6-943.7)$ & $371.8(124.6-1262.6)$ & $<0.001$ \\
\hline IgM, mg/dl & $83.1 \pm 56.1$ & $159.3 \pm 147.2$ & 0.012 \\
\hline
\end{tabular}

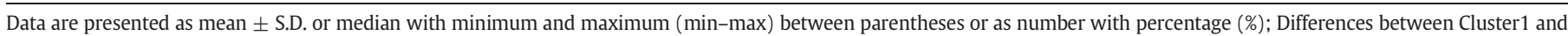

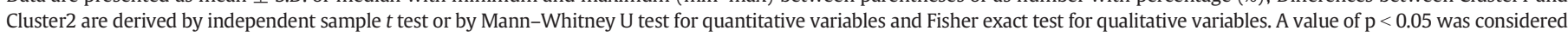
significant. 
B lymphocytes and plasma IgM levels. Among the immune parameters used in the CA, Cytomegalovirus (CMV) serostatus was not considered because most of the centenarians (95.7\%) were CMV positive. This analysis allowed us to identify two groups of centenarians, i.e. Cluster1 consisting of 88 subjects and Cluster 2 consisting of 28 subjects. Table 1 shows that the number of the main white blood cell subsets and IgM levels were all higher in Cluster2 in comparison with Cluster1 while age and gender distribution were similar between two groups. In order to assess the impact of such core of immune parameters on survival, Kaplan-Meier survival curve for all-cause mortality was performed in Cluster1 and 2. Fig. 1A and B shows that the eight immune parameters as a whole were associated with a higher survival in centenarians belonging to Cluster2. None of these immune parameters separately considered were significantly associated with survival (Fig. 1C), indicating that the entire set of immune parameters concurs to determine a different survival. We evaluated if subjects belonging to two clusters were different from a lifestyle and anthropometric point of view. No differences were observed regarding level of education, anthropometry, functional and cognitive status except for a higher prevalence of completely continent centenarians in Cluster2 (Table 2). Moreover, the prevalence of the main age-related pathologies was similar between the two clusters (Table 3 ). Table 4 shows hematological and biochemical profiles, as well as additional immunological parameters according to CA. It is interesting to note that, in addition to the eight basic immune parameters used for the CA, more specific lymphocyte subsets such as naïve $\left(\mathrm{CD} 28^{+} / \mathrm{CD}^{-} 5^{-}\right)$, activated $/$memory $\left(\mathrm{CD} 28^{+} /\right.$ $\left.\mathrm{CD}^{+} 5^{+}\right)$and effector/memory $\left(\mathrm{CD} 28^{-} / \mathrm{CD}^{+} 5^{+}\right) \mathrm{CD}^{+}$and $\mathrm{CD} 8^{+} \mathrm{T}$ cells are different/higher in Cluster2 in comparison with Cluster1. Moreover, the CA based on the eight basic immune parameters was also capable of distinguishing Cluster1 and Cluster2 according to important metabolic parameters such as glycemia, insulin and HOMA-IR. Again, it is interesting to note that such metabolic parameters related to a better glucose handling were lower in centenarians belonging to Cluster 2 with a longer survival.

A further question was to check whether centenarians belonging to Cluster 2 were characterized by a healthier status. To this purpose, we used previously described criteria able to discriminate between oldest-old subjects with different health and functional status as well as survival probability. In particular, according to the SOF index proposed by the Study of Osteoporotic Fractures (Ensrud et al., 2008) and the Simple Model of Functional Status (SMFS) (Cevenini et al., 2013b) (see for details Materials and methods section), centenarians were classified as Robust, Pre-frail and Frail and as Healthy/independent or Unhealthy/dependent, respectively. Fig. 2 shows that Frail centenarians and Unhealthy/dependent centenarians had a significantly shorter (SOF
Table 2

Lifestyle, anthropometry, functional and cognitive status of centenarians according to CA.

\begin{tabular}{|c|c|c|c|}
\hline & Cluster1 & Cluster2 & $\mathrm{p}$ value \\
\hline \multicolumn{4}{|l|}{ Lifestyle } \\
\hline Education, years, mean \pm S.D. & $6.6 \pm 4.5$ & $7.5 \pm 5.2$ & 0.368 \\
\hline Current smokers, n (\%) & 0 & 0 & ns \\
\hline Former smokers, n (\%) & $24(27.3)$ & $5(17.9)$ & 0.316 \\
\hline Daily alcohol consumption, $\mathrm{n}(\%)$ & $35(40.7)$ & $10(35.7)$ & 0.639 \\
\hline \multicolumn{4}{|l|}{ Anthropometric features } \\
\hline Weight, $\mathrm{kg}$, mean \pm S.D. & $54.5 \pm 12.1$ & $57.3 \pm 9.6$ & 0.321 \\
\hline Height, $\mathrm{cm}$, mean \pm S.D. & $1.5 \pm 0.1$ & $1.5 \pm 0.1$ & 0.795 \\
\hline Waist circumference, $\mathrm{cm}$, mean \pm S.D. & $85.3 \pm 12.5$ & $88.6 \pm 8.4$ & 0.246 \\
\hline Hip circumference, $\mathrm{cm}$, mean \pm S.D. & $96.2 \pm 10.6$ & $97.3 \pm 7.6$ & 0.679 \\
\hline $\begin{array}{l}\text { Body mass index, BMI, } \mathrm{kg} / \mathrm{m}^{2} \\
\text { mean } \pm \text { S.D. }\end{array}$ & $23.4 \pm 4.0$ & $25.3 \pm 4.0$ & 0.072 \\
\hline \multicolumn{4}{|l|}{ Functional and cognitive status } \\
\hline \multicolumn{4}{|l|}{ ADL (5 items) } \\
\hline Not disabled, n (\%) & $20(22.7)$ & $9(32.1)$ & 0.477 \\
\hline Moderately/severely disabled, n (\%) & $68(77.3)$ & $6(67.8)$ & \\
\hline Continent, n (\%) & $27(30.7)$ & $17(60.7)$ & 0.004 \\
\hline IADL, mean \pm S.D. & $1.7 \pm 2.3$ & $2.3 \pm 2.5$ & 0.178 \\
\hline Able to perform chair stand, $\mathrm{n}(\%)$ & $11(12.9)$ & $2(7.1)$ & 0.404 \\
\hline Able to walk $500 \mathrm{~m}$ w/o help, n (\%) & $12(13.8)$ & $4(14.3)$ & 0.948 \\
\hline $\begin{array}{l}\text { Able to go up and down the stairs } \\
\text { w/o help, } n(\%)\end{array}$ & $9(10.2)$ & $1(3.6)$ & 0.278 \\
\hline Use of aids, $\mathrm{n}(\%)$ & $69(78.4)$ & $18(64.3)$ & 0.133 \\
\hline MMSE, mean \pm S.D. & $19.3 \pm 6.7$ & $18.3 \pm 7.4$ & 0.557 \\
\hline GDS, mean \pm S.D. & $5.5 \pm 3.7$ & $4.4 \pm 3.0$ & 0.226 \\
\hline
\end{tabular}

Data are presented as mean \pm S.D. or as number with percentage (\%) between parentheses. Differences between Cluster1 and Cluster2 are derived by Independent Sample $t$ test or by Mann-Whitney U test for quantitative variables and Chi square or Fisher exact test for qualitative variables. A value of $\mathrm{p}<0.05$ was considered significant.

index) or a trend to a shorter survival (SMFS) compared to Robust and Healthy/independent centenarians. Thus, the health status per se is correlated to survival in centenarians. However, when we analyzed the distribution of centenarians according to the SOF index and SMFS in Cluster1 and Cluster2, we observed unexpectedly that subjects classified as Robust, Pre-frail and Frail and as Healthy/independent or Unhealthy/dependent were similarly distributed between Cluster1 and Cluster2 (Table 5). We found that there is no interaction between the SOF index and clustering $(\mathrm{p}=0.35)$, between the Simple Model of Functional Status and clustering $(p=0.15)$, and between the SOF index and the Simple Model of Functional Status functional status $(\mathrm{p}=0.5)$ as assessed by bivariate Cox regression. These data show that the classification of centenarians based on immune parameters and those based on parameters related to frailty (SOF index) and functional and cognitive status (SMFS) do not correlate each other, despite
A

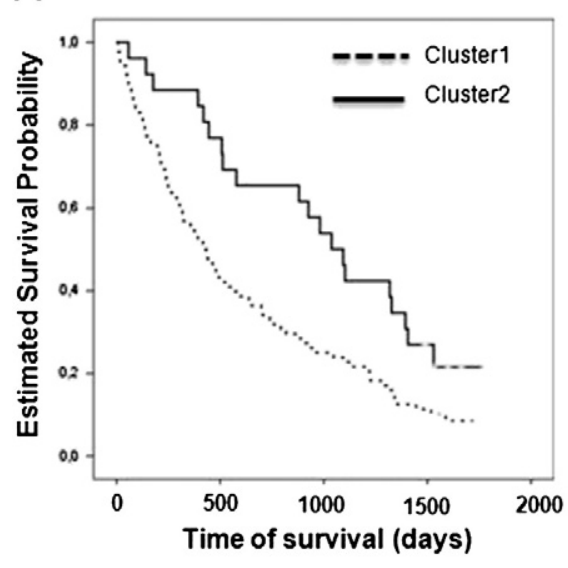

B

\begin{tabular}{|c|c|c|c|c|}
\hline & \multicolumn{4}{|c|}{ Survival time (days) } \\
\hline & $\begin{array}{l}\text { Estimate } \\
\text { (median) }\end{array}$ & $\begin{array}{l}\text { Standard } \\
\text { error }\end{array}$ & $95 \% \mathrm{Cl}$ & p-value \\
\hline $\begin{array}{l}\text { cluster1 } \\
\text { cluster2 }\end{array}$ & $\begin{array}{l}429 \\
1037\end{array}$ & $\begin{array}{l}57.2 \\
112.2\end{array}$ & $\begin{array}{l}316.8-541.1 \\
817.1-1256.9\end{array}$ & 0.008 \\
\hline \multicolumn{3}{|c|}{ 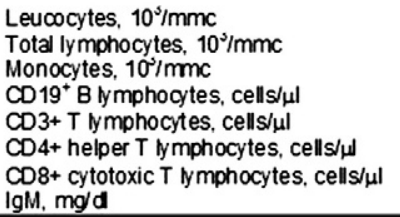 } & $\begin{array}{l}\text { Cox regression } \\
\text { coefficient } \\
-2.784 \mathrm{e}-02 \\
-2.034 \mathrm{e}-01 \\
-5.293 \mathrm{e}-01 \\
-2.431 \mathrm{e}-03 \\
-3.669 \mathrm{e}-04 \\
-5.647 \mathrm{e}-04 \\
-3.620 \mathrm{e}-04 \\
-2.132 \mathrm{e}-03\end{array}$ & $\begin{array}{l}\text { p-value } \\
0.612 \\
0.228 \\
0.504 \\
0.134 \\
0.083 \\
0.123 \\
0.379 \\
0.125\end{array}$ \\
\hline
\end{tabular}

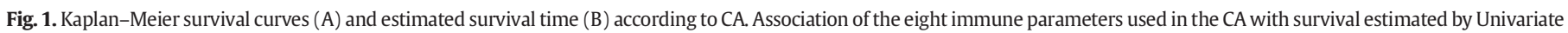
Cox regression model (C). 
Table 3

Prevalence of major diseases and pharmacological therapy of centenarians according to CA.

\begin{tabular}{|c|c|c|c|}
\hline & Cluster1 & Cluster2 & $\mathrm{p}$ value \\
\hline \multicolumn{4}{|l|}{ Pathologies } \\
\hline $\begin{array}{l}\text { Past myocardial infarction, stroke, cerebral } \\
\text { thrombosis/hemorrhage, } \mathrm{n}(\%)\end{array}$ & $50(57.5)$ & $21(75.0)$ & 0.097 \\
\hline Past cancer, n (\%) & $18(20.7)$ & $3(10.7)$ & 0.235 \\
\hline Cardiovascular diseases, $\mathrm{n}(\%)^{\mathrm{a}}$ & $50(56.8)$ & $17(60.7)$ & 0.716 \\
\hline Hypertension, n (\%) & $53(60.2)$ & $16(57.1)$ & 0.772 \\
\hline Chronic obstructive pulmonary disease, $\mathrm{n}(\%)$ & $11(12.5)$ & $3(10.7)$ & 0.801 \\
\hline Hypercholesterolemia, n (\%) & $12(13.8)$ & $7(25.0)$ & 0.165 \\
\hline Diabetes, n (\%) & $6(6.8)$ & $1(3.6)$ & 0.530 \\
\hline Hyperthyroidism, n (\%) & 0 & $2(7.1)$ & 0.057 \\
\hline Hypothyroidism, n (\%) & $2(2.3)$ & $3(10.7)$ & 0.090 \\
\hline Osteoporosis, n (\%) & $11(12.6)$ & $9(32.1)$ & 0.018 \\
\hline Chronic renal insufficiency, $\mathrm{n}(\%)$ & $10(11.4)$ & $2(7.1)$ & 0.523 \\
\hline \multicolumn{4}{|l|}{ Pharmacological therapy } \\
\hline Number of medication, mean $\pm S D$ & $4.6 \pm 3.2$ & $4.6 \pm 2.3$ & 0.888 \\
\hline Cardiovascular therapy, n (\%) & $59(67.0)$ & $17(60.7)$ & 0.539 \\
\hline Hypotensive therapy, n (\%) & $51(58.0)$ & $17(60.7)$ & 0.796 \\
\hline Anti-diabetic therapy, n (\%) & $7(8.0)$ & $2(7.1)$ & 0.889 \\
\hline Lipid-lowering therapy, $\mathrm{n}(\%)$ & $1(1.1)$ & $0(0.0)$ & 0.571 \\
\hline
\end{tabular}

Data are presented as mean \pm S.D. or as number with percentage (\%) between parentheses. Differences between Cluster1 and Cluster2 are derived by Independent Sample $t$ test and Chi square or Fisher exact tests for quantitative and qualitative variables respectively. A value of $\mathrm{p}<0.05$ was considered significant.

${ }^{\text {a }}$ Heart failure, irregular heart rhythm and angina.

being correlated with survival when considered separately. Moreover, in centenarians the SMFS classification loses its discrimination power, as survival is not correlated with the combination of MMSE and ADL used by this index (Table 6).

\section{Discussion}

Centenarians are rare and exceptional individuals characterized by a peculiar phenotype and are the best example of healthy aging in humans. Most of them have escaped and/or substantially delayed the onset of major age-related diseases but, although in relatively good shape, many of them show signs of frailty due to their extreme age. They also show a great heterogeneity and the evaluation of their health
Table 5

Distribution of centenarians according to frailty (SOF index) and Simple Model of Functional Status in Cluster1 and Cluster2.

\begin{tabular}{lccc}
\hline & Cluster1 & Cluster2 & p value \\
\hline Frailty (SOF index) & & & \\
Robust, n (\%) & $6(7.3)$ & $3(1.7)$ & 0.801 \\
Pre-frail, n (\%) & $26(31.7)$ & $9(33.3)$ & \\
Frail, n (\%) & $50(61.0)$ & $17(63.0)$ & \\
Simple Model of Functional Status & & & \\
Healthy/independent, n (\%) & $15(17.0)$ & $4(14.3)$ & \\
Unhealthy/dependent, n (\%) & $73(83.0)$ & $24(85.7)$ & 0.731 \\
\hline
\end{tabular}

Data are presented as number with percentage (\%) between parentheses. Differences between Cluster 1 and Cluster 2 are derived by Fisher exact test and a value of $p<0.05$ was considered significant.

and functional status is a complex and still poorly addressed issue. Most studies have shown that socio-demographic factors (such as marital status, education, smoking, alcohol), physical and cognitive functions and self-reported health may predict mortality in nonagenarians (Nybo et al. 2003). Other studies tried to define variables which are better associated with health status and survival in nonagenarians and centenarians (Cevenini et al., 2013b, 2013c; Franceschi et al., 2000).

Within this scenario, the purpose of the present work was to understand if immune status is associated with survival and health status in centenarians.

To this aim, for the first time, a consistent group of centenarians have been concomitantly characterized from an immunological point of view, as well as for their health and functional status, and followed-up for 5 years regarding survival. On the basis of previous knowledge on the immune characteristics of very old subjects (Nilsson et al., 2003; Olsson et al., 2000; Wikby et al., 2002) we focused on a core of fundamental and basic immune parameters such as number of leucocytes, monocytes, total lymphocytes, $\mathrm{CD} 3^{+} \mathrm{T}$ lymphocytes, $\mathrm{CD} 4^{+}$helper and $\mathrm{CD}^{+}$cytotoxic T lymphocytes, CD19 ${ }^{+}$B lymphocytes and levels of IgM in order to distinguish discrete immune phenotypes.

The most important findings were the following: i. a hierarchical cluster analysis was able to define two subgroups of centenarians characterized by high or low values of all these parameters, respectively; ii. these two groups were characterized by a statistically different five-

Table 4

Hematological and biochemical parameters of centenarians according to CA

\begin{tabular}{|c|c|c|c|}
\hline & Cluster1 & Cluster2 & $\mathrm{p}$ value \\
\hline \multicolumn{4}{|l|}{ Hematological parameters } \\
\hline Platelets $\left(10^{3} / \mu \mathrm{l}\right)$ & $238.52 \pm 77.31$ & $268.63 \pm 62.61$ & 0.064 \\
\hline Erythrocytes $\left(10^{3} / \mu \mathrm{l}\right)$ & $4.20 \pm 0.54$ & $4.16 \pm 0.48$ & 0.760 \\
\hline Hemoglobin $(\mathrm{g} / \mathrm{dl})$ & $12.45 \pm 1.50$ & $12.33 \pm 1.37$ & 0.694 \\
\hline Hematocrit (\%) & $36.80 \pm 5.52$ & $37.12 \pm 4.25$ & 0.779 \\
\hline Red cell distribution width (\%) & $14.66 \pm 1.36$ & $14.24 \pm 1.43$ & 0.164 \\
\hline $\mathrm{CD}^{+} / \mathrm{CD}^{+}$ratio & $2.0(0.4-6.5)$ & $2.2(0.5-11.3)$ & 0.402 \\
\hline $\mathrm{CD}^{+}{ }^{+}$naïve T cells, cells/ $\mu \mathrm{l}$ & $107.0(11.8-474.6)$ & $263.3(0.9-850.6)$ & $<0.001$ \\
\hline $\mathrm{CD}^{+}$naïve $\mathrm{T}$ cells, cells/ $\mu \mathrm{l}$ & $8.46(0.05-155.8)$ & $28.2(1.8-400.7)$ & 0.001 \\
\hline $\mathrm{CD}^{+}{ }^{+}$activated/memory $\mathrm{T}$ cells, cells/ $\mu \mathrm{l}$ & $271.3(82.4-615.5)$ & $440.3(227.2-864.1)$ & $<0.001$ \\
\hline 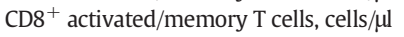 & $78.9(10.7-570.4)$ & $97.3(31.7-447.5)$ & 0.022 \\
\hline $\mathrm{CD}^{+}{ }^{+}$Effector/Memory T cells, cells/ $\mu \mathrm{l}$ & $45.1(0.5-380.0)$ & $152.3(9.9-516.7)$ & $<0.001$ \\
\hline $\mathrm{CD}^{+}$effector/memory T cells, cells/ $\mu \mathrm{l}$ & $120.3(2.7-729.8)$ & $198.0(9.4-749.1)$ & 0.008 \\
\hline \multicolumn{4}{|l|}{ Biochemical parameters } \\
\hline Creatinine (mg/dl) & $0.99 \pm 0.30$ & $1.03 \pm 0.37$ & 0.544 \\
\hline Total cholesterol (mg/dl) & $186.16 \pm 42.14$ & $194.07 \pm 36.44$ & 0.374 \\
\hline HDL-cholesterol (mg/dl) & $48.05 \pm 13.92$ & $44.14 \pm 10.67$ & 0.176 \\
\hline Triglycerides (mg/dl) & $122.87 \pm 473.42$ & $125.46 \pm 54.91$ & 0.864 \\
\hline Glycemia (mg/dl) & $87.53 \pm 23.54$ & $75.32 \pm 9.70$ & $<0.001$ \\
\hline Insulin $(\mu \mathrm{IU} / \mathrm{ml})$ & $9.8 \pm 11.9$ & $6.3 \pm 3.4$ & 0.019 \\
\hline HOMA-IR & $2.3 \pm 3.6$ & $1.6 \pm 0.7$ & 0.007 \\
\hline Insulin resistant subjects, n (\%) & $17(19.5)$ & $2(7.1)$ & 0.124 \\
\hline
\end{tabular}

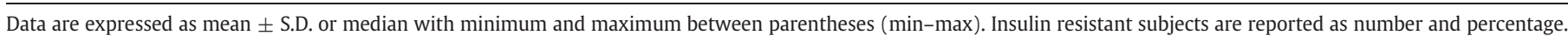

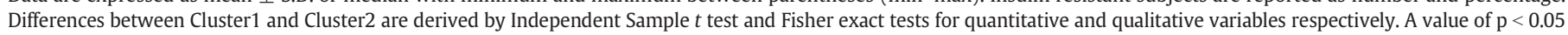
was considered significant. 
A

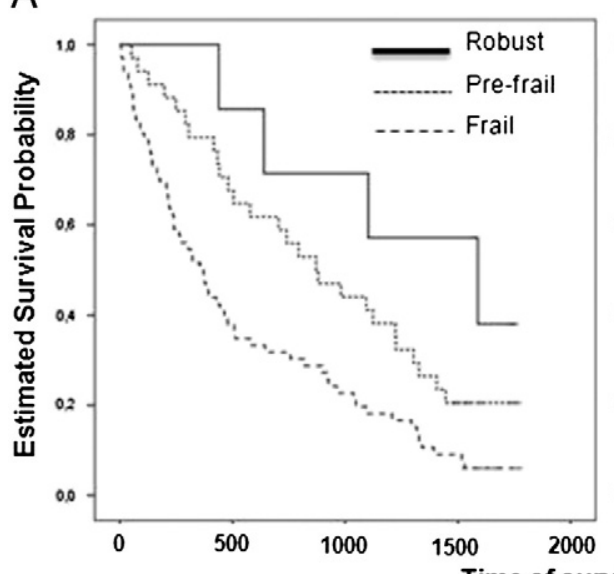

B

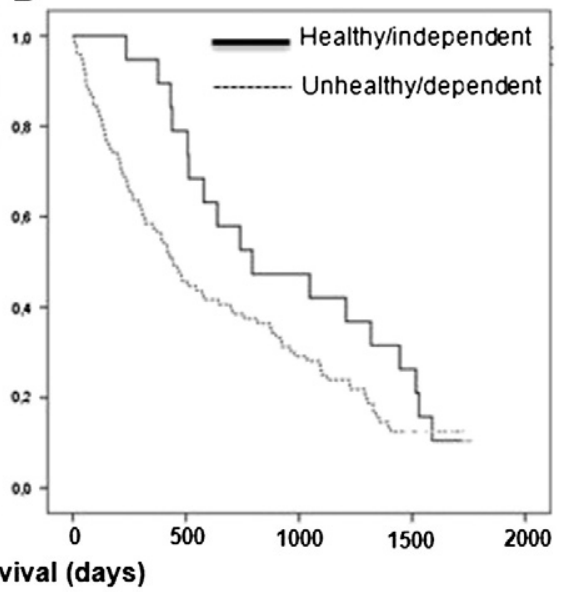

C

\begin{tabular}{lcccc}
\hline & \multicolumn{4}{c}{ Survival time (days) } \\
& $\begin{array}{l}\text { Estimate } \\
\text { (median) }\end{array}$ & $\begin{array}{l}\text { Standard } \\
\text { error }\end{array}$ & $95 \% \mathrm{Cl}$ & p-value \\
\hline Robust & 1588.0 & 508.6 & $591.1-2584.9$ & \\
Pre-frail & 871.0 & 175.6 & $526.7-1215.3$ & $<0.001$ \\
Frail & 357.0 & 63.5 & $232.6-481.4$ & \\
\hline Healthy/independent & 793.0 & 296.0 & $212.8-1373.1$ & \multirow{2}{*}{0.147} \\
Unhealthy/dependent & 441.0 & 55.3 & $332.5-549.5$ & \\
\hline
\end{tabular}

Fig. 2. Kaplan-Meier survival curves according to frailty (SOF index) (A) and to Simple Model of Functional Status (B) and estimated survival time (C).

year survival; iii. Cluster2, where all the immune parameters were higher than Cluster1, showed a longer survival; iv. the two centenarian clusters resulted different for other important immune (naïve, activated/memory and effector/memory T cells) (Fagnoni et al., 2000; Nasi et al., 2006) and metabolic parameters (glycemia, insulin and HOMA-IR) in accord with previous observations that healthy centenarians have a peculiar immune phenotype, a preserved insulin action and a lower incidence of type 2 diabetes compared to aged subjects (Motta et al., 2005; Paolisso et al., 1996; Takayama et al., 2007); v. unexpectedly, frailty as well as functional and cognitive status, despite the capability of predicting survival did not show any significant correlation with the immune clustering. Indeed, the health status of centenarians belonging to Cluster2 and displaying a longer survival is similar to that of centenarians belonging to Cluster1. In fact no differences emerged regarding anthropometry, functional and cognitive status and prevalence of major age-related diseases except for continence and osteoporosis.

As far as the immune status of centenarians is concerned, congruent with the experimental results, a low total lymphocyte count as well as $\mathrm{CD}^{+}$and $\mathrm{CD}^{+}$lymphocyte subsets counts increased mortality risk in $85+$ subjects (Izaks et al., 2003). Moreover, literature data showed

Table 6

Unadjusted hazard ratios (HR) and 95\% confidence intervals $(\mathrm{CI})$ for centenarians according to CA, frailty (SOF index) and Simple Model of Functional Status estimated by multivariate Cox regression model.

\begin{tabular}{llll}
\hline Variables & HR & $(95 \% \mathrm{CI})$ & p value \\
\hline Cluster1 & Reference & & \\
Cluster2 & 0.410 & $(0.244-0.688)$ & 0.001 \\
Robust & Reference & & \\
Pre-frail & 2.366 & $(0.819-6.833)$ & 0.111 \\
Frail & 4.418 & $(1.717-13.523)$ & 0.003 \\
Healthy/independent & Reference & & \\
Unhealthy/dependent & 1.538 & $(0.905-2.617)$ & 0.112 \\
\hline
\end{tabular}

that higher $\mathrm{CD} 4^{+} \mathrm{T}$ cell and $\mathrm{B}$ cell percentages were associated with increased survival in octogenarians and nonagenarians (Ferguson et al., 1995; Huppert et al., 2003; Wikby et al., 1998, 2002). Our data show that centenarians with a longer survival were characterized by a high $\mathrm{CD}^{+} \mathrm{T}$ cell count. This finding differs from previous data showing that low CD8 percentage was associated with longer survival (Ferguson et al., 1995; Wikby et al., 1998, 2002). We also found that the CD4/CD8 ratio, previously considered as a key parameter to define IRP and able to predict mortality, did not change between centenarians belonging to Cluster1 and Cluster2 (Table 4). Indeed, centenarians belonging to Cluster2 showed high number of both $\mathrm{CD}^{+}$helper and $\mathrm{CD} 8^{+}$cytotoxic $\mathrm{T}$ lymphocytes. Finally, a major result of our investigation is that none of the eight immune variables singly considered was significantly associated with survival probability indicating that the entire set of the abovementioned variables constitutes an immune parameter pattern able to determine a different survival expectancy in centenarians.

As far as the lack of correlation between the immune status and health in centenarians, the results here presented are in agreement with previous studies showing that IRP was not influenced by morbidity in nonagenarians (Nilsson et al., 2003).

It is interesting to note that in centenarians belonging to Cluster2 a favorable immune profiling was accompanied by a favorable metabolic parameter (glycemia, insulin and HOMA-IR) suggesting that a well preserved glucose handling is likely important not only to avoid/postpone diabetes but also as a functional pathway capable of supplying energy to the immune system and its cells.

In conclusion, the main result of our investigation is that high values of basic immunological parameters and of important $\mathrm{T}$ cell subsets (naïve, activated/memory and effector/memory T cells) correlate with five-year survival in centenarians, independent of other phenotypic characteristics (frailty, cognitive and functional abilities) which per se are associated with survival. As far as we know, this unexpected 
biological scenario is unique and never described before. The biological implications of these results can be far reaching in order to explain the biological status underpinning extreme longevity and for understanding the driving forces responsible for mortality in subjects who reached the extreme limit of lifespan in humans. We hypothesize that a main characteristic of the centenarians is a progressive disconnection and loss of biological coherence among the different functions of the body. We can speculate that the mortality outcome in centenarians is the result of the failure of any of these domains which apparently follow an independent age-related trajectory.

\section{Conflict of interest}

No conflicts of interest, financial or otherwise, are declared by the authors.

\section{Acknowledgments}

The research leading to these results has received funding from the European Union's Seventh Framework Programme (FP7/2007-2011, FP7-Health-F5-2012, FP7/2007-2013) under grant agreement $n$. 259679 (IDEAL) to CF, n. 305280 (MIMOmics) to GC and CF, n. 289517 (FibeBiotics) to GC, from MIUR (PRIN 2006) to D. Monti, CF, and D. Mari and from MIUR (PRIN2009) to CF and D. Mari.

We also thank DiaSorin (Saluggia, Italy) for the evaluation of insulin levels and anti-CMV IgG.

\section{References}

Alberti, S., Cevenini, E., Ostan, R., Capri, M., Salvioli, S., Bucci, L., Ginaldi, L., De Martinis, M., Franceschi, C., Monti, D., 2006. Age-dependent modifications of type 1 and type 2 cytokines within virgin and memory CD4 ${ }^{+}$T cells in humans. Mech. Ageing Dev. 127 (6), 560-566 (Jun).

Cevenini, E., Monti, D., Franceschi, C., 2013a. Inflamm-ageing. Curr. Opin. Clin. Nutr. Metab. Care 16 (1), 14-20 (Jan, a).

Cevenini, E., Cotichini, R., Stazi, M.A., Toccaceli, V., Scurti, M., Mari, V., Berardelli, M., Passarino, G., Jeune, B., Franceschi, C., 2013b. GEHA Project Consortium. How to classify the oldest old according to their health status: A study on 1160 subjects belonging to $55290+$ Italian sib-ships characterized by familial longevity recruited within the GEHA EU Project. Mech. Ageing Dev. 134 (11-12), 560-569 (Nov-Dec, b).

Cevenini, E., Cotichini, R., Stazi, M.A., Toccaceli, V., Palmas, M.G., Capri, M., De Rango, F., Dato, S., Passarino, G., Jeune, B., Franceschi, C., 2013c. The GEHA Project Consortium. Health status and 6 years survival of $55290+$ Italian sib-ships recruited within the EU Project GEHA (GEnetics of Healthy Ageing). Age (Dordr.) 10 (Dec, c).

Colonna-Romano, G., Buffa, S., Bulati, M., Candore, G., Lio, D., Pellicanò, M., Vasto, S. Caruso, C., 2010. B cells compartment in centenarian offspring and old people. Curr. Pharm. Des. 16 (6), 604-608.

Csuka, M., McCarty, D.J., 1985. Simple method for measurement of lower extremity muscle strength. Am. J. Med. 78 (1), 77-81 (Jan).

Ensrud, K.E., Ewing, S.K., Taylor, B.C., Fink, H.A., Cawthon, P.M., Stone, K.L., Hillier, T.A., Cauley, J.A., Hochberg, M.C., Rodondi, N., Tracy, J.K., Cummings, S.R., 2008. Comparison of 2 frailty indexes for prediction of falls, disability, fractures, and death in older women. Arch. Intern. Med. 168 (4), 382-389 (Feb 25).

Evert, J., Lawler, E., Bogan, H., Perls, T., 2003. Morbidity profiles of centenarians: survivors, delayers, and escapers. J. Gerontol. A Biol. Sci. Med. Sci. 58 (3), 232-237 (Mar).

Fagnoni, F.F., Vescovini, R., Passeri, G., Bologna, G., Pedrazzoni, M., Lavagetto, G., Casti, A., Franceschi, C., Passeri, M., Sansoni, P., 2000. Shortage of circulating naive CD8(+) $\mathrm{T}$ cells provides new insights on immunodeficiency in aging. Blood 95 (9), 2860-2868 (May 1).

Ferguson, F.G., Wikby, A., Maxson, P., Olsson, J., Johansson, B., 1995. Immune parameters in a longitudinal study of a very old population of Swedish people: a comparison between survivors and nonsurvivors. J. Gerontol. A Biol. Sci. Med. Sci. 50 (6), B378-B382 (Nov).

Fillenbaum, G.G., 1996. Functional ability, In: Ebrahim, S., Kalache, A. (Eds.), Epidemiology in Old Age, 1st ed. BMJ Publishing Group, London, pp. 228-235.

Folstein, M.F., Folstein, S.E., McHugh, P.R., 1975. "Mini-mental state". A practical method for grading the cognitive state of patients for the clinician. J. Psychiatr. Res. 12 (3), 189-198 (Nov).

Franceschi, C., Monti, D., Sansoni, P., Cossarizza, A., 1995. The immunology of exceptional individuals: the lesson of centenarians. Immunol. Today. 16 (1), 12-16 (Jan).

Franceschi, C., Motta, L., Motta, M., Malaguarnera, M., Capri, M., Vasto, S., Candore, G., Caruso, C., 2008. IMUSCE. The extreme longevity: the state of the art in Italy. Exp. Gerontol. 43 (2), 45-52 (Feb).

Franceschi, C., Motta, L., Valensin, S., Rapisarda, R., Franzone, A., Berardelli, M., Motta, M., Monti, D., Bonafè, M., Ferrucci, L., Deiana, L., Pes, G.M., Carru, C., Desole, M.S., Barbi, C., Sartoni, G., Gemelli, C., Lescai, F., Olivieri, F., Marchegiani, F., Cardelli, M., Cavallone, L., Gueresi, P., Cossarizza, A., Troiano, L., Pini, G., Sansoni, P., Passeri, G., Lisa, R.,
Spazzafumo, L., Amadio, L., Giunta, S., Stecconi, R., Morresi, R., Viticchi, C., Mattace, R., De Benedictis, G., Baggio, G., 2000. Do men and women follow different trajectories to reach extreme longevity? Italian Multicenter Study on Centenarians (IMUSCE) Aging (Milano) 12 (2), 77-84 (Apr).

Frasca, D., Blomberg, B.B., 2011. Aging affects human B cell responses. J. Clin. Immunol. 31 (3), 430-435 (Jun)

Huppert, F.A., Pinto, E.M., Morgan, K., Brayne, C., 2003. Survival in a population sample is predicted by proportions of lymphocyte subsets. Mech. Ageing Dev. 124 (4), 449-451 (Apr).

Izaks, G.J., Remarque, E.J., Becker, S.V., Westendorp, R.G., 2003. Lymphocyte count and mortality risk in older persons. The Leiden 85-Plus study. J. Am. Geriatr. Soc. 51 (10), 1461-1465 (Oct, Erratum in: J Am Geriatr Soc. 2003 Dec;51(12):1825).

Jeune, B., 2002. Living longer-but better? Aging Clin. Exp. Res. 14 (2), 72-93 (Apr).

Katz, S., Downs, T.D., Cash, H.R., Grotz, R.C., 1970. Progress in development of the index of ADL. Gerontologist 10 (1), 20-30 (Spring).

Lawton, M.P., Brody, E.M., 1969. Assessment of older people: self-maintaining and instrumental activities of daily living. Gerontologist 9 (3), 179-186 (Autumn).

Matthews, D.R., Hosker, J.P., Rudenski, A.S., Naylor, B.A., Treacher, D.F., Turner, R.C., 1985 Homeostasis Model Assessment: insulin resistance and beta-cell function from fasting plasma glucose and insulin concentrations in man. Diabetologia 28 (7), 412-419 (Jul).

Motta, M., Bennati, E., Ferlito, L., Malaguarnera, M., Motta, L., 2005. Italian Multicenter Study on Centenarians (IMUSCE). Successful aging in centenarians: myths and reality Arch. Gerontol. Geriatr. 40 (3), 241-251 (May-Jun).

Nasi, M., Troiano, L., Lugli, E., Pinti, M., Ferraresi, R., Monterastelli, E., Mussi, C., Salvioli, G. Franceschi, C., Cossarizza, A., 2006. Thymic output and functionality of the IL-7/IL-7 receptor system in centenarians: implications for the neolymphogenesis at the limit of human life. Aging Cell 5 (2), 167-175 (Apr).

Nilsson, B.O., Ernerudh, J., Johansson, B., Evrin, P.E., Löfgren, S., Ferguson, F.G., Wikby, A. 2003. Morbidity does not influence the T-cell immune risk phenotype in the elderly: findings in the Swedish NONA immune study using sample selection protocols. Mech. Ageing Dev. 124 (4), 469-476 (Apr).

Nybo, H., Petersen, H.C., Gaist, D., Jeune, B., Andersen, K., McGue, M., Vaupel, J.W. Christensen, K., 2003. Predictors of mortality in 2249 nonagenarians-the Danish 1905-cohort survey. J. Am. Geriatr. Soc. 51 (10), 1365-1373 (Oct).

Olivieri, F., Spazzafumo, L., Antonicelli, R., Marchegiani, F., Cardelli, M., Sirolla, C., Galeazzi, R., Giovagnetti, S., Mocchegiani, E., Franceschi, C., 2008. Combination of biomarkers to predict mortality in elderly patients with myocardial infarction. Mech. Ageing Dev. 129 (4), 231-237 (Apr).

Olsson, J., Wikby, A., Johansson, B., Löfgren, S., Nilsson, B.O., Ferguson, F.G., 2000. Age-related change in peripheral blood T-lymphocyte subpopulations and cytomegalovirus infection in the very old: the Swedish longitudinal OCTO immune study. Mech. Ageing Dev. 121 (1-3), 187-201 (Dec 20).

Ostan, R., Bucci, L., Capri, M., Salvioli, S., Scurti, M., Pini, E., Monti, D., Franceschi, C., 2008. Immunosenescence and immunogenetics of human longevity. Neuroimmunomodulation 15 (4-6), 224-240.

Paolisso, G., Gambardella, A., Ammendola, S., D'Amore, A., Balbi, V., Varricchio, M. D'Onofrio, F., 1996. Glucose tolerance and insulin action in healthy centenarians. Am. J. Physiol. 270 (5 Pt 1), E890-E894 (May).

Paolisso, G., Barbieri, M., Rizzo, M.R., Carella, C., Rotondi, M., Bonafè, M., Franceschi, C. Rose, G., De Benedictis, G., 2001. Low insulin resistance and preserved beta-cell function contribute to human longevity but are not associated with TH-INS genes. Exp. Gerontol. 37 (1), 149-156 (Dec).

Passeri, G., Pini, G., Troiano, L., Vescovini, R., Sansoni, P., Passeri, M., Gueresi, P., Delsignore R., Pedrazzoni, M., Franceschi, C., 2003. Low vitamin D status, high bone turnover, and bone fractures in centenarians. J. Clin. Endocrinol Metab. 88 (11) 5109-5115 (Nov).

Pawelec, G., Koch, S., Franceschi, C., Wikby, A., 2006. Human immunosenescence: does it have an infectious component? Ann. N. Y. Acad. Sci. 1067, 56-65 (May).

Salvioli, S., Capri, M., Bucci, L., Lanni, C., Racchi, M., Uberti, D., Memo, M., Mari, D., Govoni, S. Franceschi, C., 2009. Why do centenarians escape or postpone cancer? The role of IGF-1, inflammation and p53. Cancer Immunol. Immunother. 58 (12), 1909-1917 (Dec)

Sansoni, P., Vescovini, R., Fagnoni, F., Biasini, C., Zanni, F., Zanlari, L., Telera, A., Lucchini, G. Passeri, G., Monti, D., Franceschi, C., Passeri, M., 2008. The immune system in extreme longevity. Exp. Gerontol. 43 (2), 61-65 (Feb).

Strindhall, J., Nilsson, B.O., Löfgren, S., Ernerudh, J., Pawelec, G., Johansson, B., Wikby, A., 2007. No immune risk profile among individuals who reach 100 years of age: findings from the Swedish NONA immune longitudinal study. Exp. Gerontol. 42 (8), 753-761 (Aug).

Takayama, M., Hirose, N., Arai, Y., Gondo, Y., Shimizu, K., Ebihara, Y., Yamamura, K. Nakazawa, S., Inagaki, H., Masui, Y., Kitagawa, K., 2007. Morbidity of Tokyo-area centenarians and its relationship to functional status. J. Gerontol. A Biol. Sci. Med. Sci. 62 (7), 774-782 (Jul).

Ward Jr., J.H., 1963. Hierarchical grouping to optimize an objective function. J. Am. Stat Assoc. 58, 236-244.

Wikby, A., Maxson, P., Olsson, J., Johansson, B., Ferguson, F.G., 1998. Changes in CD8 and CD4 lymphocyte subsets, T cell proliferation responses and non-survival in the very old: the Swedish longitudinal OCTO-immune study. Mech. Ageing Dev. 102 (2-3), 187-198 (May 15).

Wikby, A., Johansson, B., Olsson, J., Löfgren, S., Nilsson, B.O., Ferguson, F., 2002. Expansions of peripheral blood CD8 T-lymphocyte subpopulations and an association with cytomegalovirus seropositivity in the elderly: the Swedish NONA immune study. Exp. Gerontol. 37 (2-3), 445-453 (Jan-Mar).

World Population Prospects, 2013. The 2012 Revision. United Nations, New York.

Yesavage, J.A., Brink, T.L., Rose, T.L., Lum, O., Huang, V., Adey, M., Leirer, V.O., 1982-1983. Development and validation of a geriatric depression screening scale: a preliminary report. J. Psychiatr. Res. 17 (1), 37-49. 